\title{
Unusual diagnosis in a patient with minor ankle trauma
}

\author{
Zoë Piggott, MD*; Donna Clark, MD*
}

\begin{abstract}
We present the case of a 23 year-old male who sustained an anterior tibial artery pseudoaneurysm after an apparently innocuous soccer injury. The patient presented with sudden onset severe pain and swelling one week after the injury. The diagnosis was made using duplex ultrasound, and confirmed with CT angiography. Definitive management consisted of endovascular platinum microcoiling. One year later, the patient is asymptomatic and remains active. A review of the epidemiology, diagnosis, and treatment of arterial pseudoaneurysm is presented. Bedside ultrasound in the emergency department may be a useful adjunct in the early identification of pseudoaneurysms.
\end{abstract}

\section{RÉSUMÉ}

Sera exposé ici un cas de faux anévrisme de l'artère tibiale antérieure chez un jeune homme de 23 ans, ayant subi une blessure en apparence inoffensive au soccer. Une semaine après l'accident, le patient est venu consulter au service des urgences pour l'apparition soudaine de fortes douleurs et de l'enflure. Le diagnostic a été posé à l'aide d'une échographie Doppler en mode duplex, puis confirmé à l'aide d'une angiographie par tomodensitométrie. On a procédé au traitement de référence, soit à la pose d'une microspire endovasculaire de platine. Un an plus tard, le patient ne présente pas de symptômes et il est encore actif. Les auteurs font état, dans l'article, d'un examen de la documentation sur l'épidémiologie, le diagnostic et le traitement des faux anévrismes artériels. Enfin, l'échographie au chevet réalisée au service des urgences peut s'avérer un examen complémentaire utile dans le diagnostic précoce des faux anévrismes.

Keywords: pseudoaneurysm, tibial artery, ultrasound

\section{CASE PRESENTATION}

A previously healthy 23-year-old man presented to the emergency department (ED) during the night, seven days after sustaining a left ankle injury during a soccer match when another player inadvertently kicked him. His vital signs at triage were as follows: heart rate 75 beats/minute, blood pressure $177 / 101 \mathrm{~mm} \mathrm{Hg}$, respiratory rate 22 breaths/minute, $\mathrm{O} 2$ sat $98 \%$ on room air, temperature $36.6{ }^{\circ} \mathrm{C}$. He complained of severe pain. The patient did not recall any specific inversion or eversion mechanism during the injury; he described it as an "ankle-to-ankle collision" while running. He was unable to continue playing or to weight-bear. He had attended a sports medicine clinic the day after the injury. At that time, the ankle/foot were described as markedly swollen but neurovascularly intact, with both medial and lateral ankle tenderness. $\mathrm{X}$-rays completed there did not show any fracture, and he was diagnosed with an ankle sprain. Initial treatment consisted of immobilization in a below-knee back slab, crutches, and oral naproxen for pain control. The patient had been compliant with treatment, and denied any weight-bearing on the injured limb at home. He reported that his symptoms, including local swelling, had been steadily improving all week until the sudden onset of severe ankle pain while watching television with his foot elevated, approximately four hours before his ED presentation. He was not experiencing fever, shortness of breath, chest pain, or paresthesia. He also denied any chronic medical conditions, allergies, or illicit drug use.

On examination, the patient was pale, diaphoretic, and experiencing severe pain. He remained hypertensive with a blood pressure of $168 / 98 \mathrm{~mm} \mathrm{Hg}$; vital signs were otherwise normal. The anterolateral aspect of the left ankle was markedly swollen, with extensive purple contusions extending over the posterolateral ankle and lateral foot (Figure 1). The dorsalis pedis and posterior tibialis pulses were present; the skin of the foot and toes was pink, warm, and well-perfused with normal capillary refill. Skin temperature was not appreciably different than the contralateral foot. No marked erythema, lymphangitis, pustules, abrasions or other skin lesions were noted. There was extreme hyperalgesia with testing of light touch over the dorsum of

From the *Emergency Medicine, University of Manitoba, Winnipeg, MB.

Correspondence to: Zoë Piggott, Room L1019, St. Boniface Hospital, Winnipeg, MB, R2H 2A6; E-mail: zoepiggott@gmail.com 


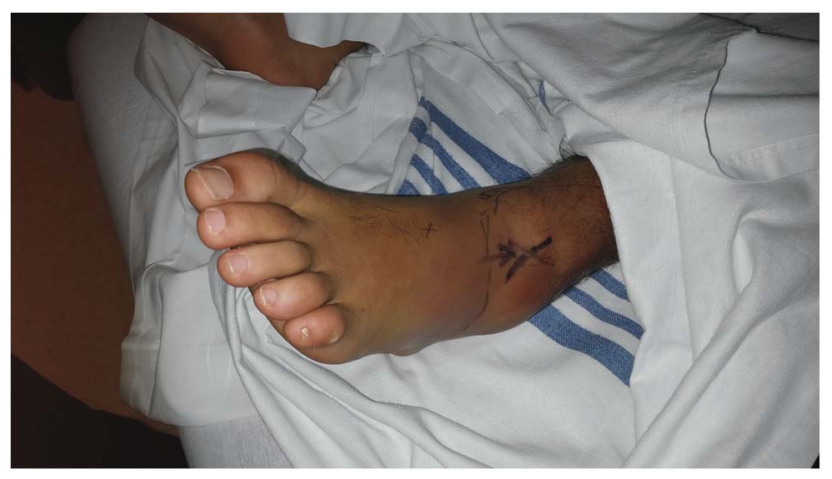

Figure 1. Clinical image of patient's affected ankle, with surface location of pseudoaneurysm marked with large $X$.

the ankle and foot, roughly corresponding to the distal distribution of the superior peroneal nerve. Sensation in the lower extremity was otherwise grossly normal. The patient was able to actively flex and extend his left toes, and demonstrate small degrees of active plantar- and dorsiflexion, inversion, and eversion of the left ankle. However, complete assessment of motor function during this initial examination was precluded by significant patient discomfort.

Initial ED management consisted of oral and parenteral analgesia with acetaminophen, ketorolac, and morphine, as well as intravenous ceftriaxone. X-rays revealed significant soft tissue swelling over and around the lateral malleolus, with a few well-corticated ossific densities in the swollen tissue. No fracture or air in the tissue was identified. Laboratory tests were unremarkable. The differential diagnosis included an expanding hematoma secondary to vascular injury, abscess, DVT, and complex regional pain syndrome.

Duplex ultrasound performed in the radiology suite the following morning (eighth day after initial injury) revealed a left anterior tibial artery pseudoaneurysm at the level of the ankle measuring $2.94 \times 1.86 \mathrm{~cm}$, with a $5.6 \times 1.9 \mathrm{~cm}$ hematoma overlying the lateral ankle (Figures 2 and 3). Diagnostic ultrasound images of the lesion were obtained by scanning over skin marked with the large $X$ (Figure 1), corresponding to the area of maximal swelling and pain. Distal flow was identified within the dorsalis pedis artery. The diagnosis was confirmed with CT angiography, which demonstrated a large pseudoaneurysm arising from the dorsal-lateral aspect of the proximal dorsalis pedis artery. Of note, after imaging the patient was re-examined and found to have an easily audible bruit in the area of the anterolateral ankle and dorsum of the foot, overlying the pseudoaneurysm.

Definitive management, consisting of embolization of the pseudoaneurysm with platinum microembolization coils, was performed in the interventional radiology suite the same day (Figure 4).

\section{DISCUSSION}

Lower extremity arterial injuries are uncommon, affecting an estimated $0.39 \%$ of patients admitted to hospital with traumatic injuries. ${ }^{1}$ The majority of these patients have suffered significant lower extremity trauma. In one recent retrospective review, $78.4 \%$ of patients with lower extremity arterial injuries had other lower extremity injuries, and $35.4 \%$ had injured other body regions. ${ }^{1}$ Predictably, patients presenting with severe lower extremity trauma remain at high risk of associated arterial injury, with an incidence of $57.1 \%$ reported in this patient population. ${ }^{2}$ The anterior tibial artery is most commonly injured (31.9\% of patients). ${ }^{2,3}$

In ambulatory patients, injury of the anterior tibial artery can occur as the result of routine procedures, minor trauma, or concomitant medical disease. Such injuries, particularly pseudoaneurysms, are rare but well-recognized complications of ankle arthroscopy, with a reported incidence of $0.008 \%{ }^{4-7}$ Rarely, pseudoaneurysm of the anterior tibial artery has been described as a result of endocarditis, connective tissue disease, biopsy, and, as in our case, sports injury. ${ }^{8-13}$

Pseudoaneurysms may occur when all 3 layers of the arterial wall-intima, media, and adventitia-are damaged. This allows for extravascular hematoma collection, with formation of a surrounding fibrous wall, which communicates directly with the intra-arterial lumen. ${ }^{3,11}$ Complications of arterial pseudoaneurysms include infection, compression of surrounding neurovascular structures, limb ischemia, necrosis of overlying skin, and rupture. ${ }^{14-16}$ Pseudoaneurysms carry a higher risk of rupture than true arterial aneurysms. ${ }^{3,14-16} \mathrm{We}$ suspect that the suddenly escalating pain experienced by our patient, one week after the traumatic event, occurred when the pseudoaneurysm began to leak and/ or expand, resulting in a high-pressure collection of blood. Branches of the superficial peroneal nerve passing through the anterolateral ankle may have been compressed, explaining the exquisite hyperalgesia noted to the dorsum of the foot. 


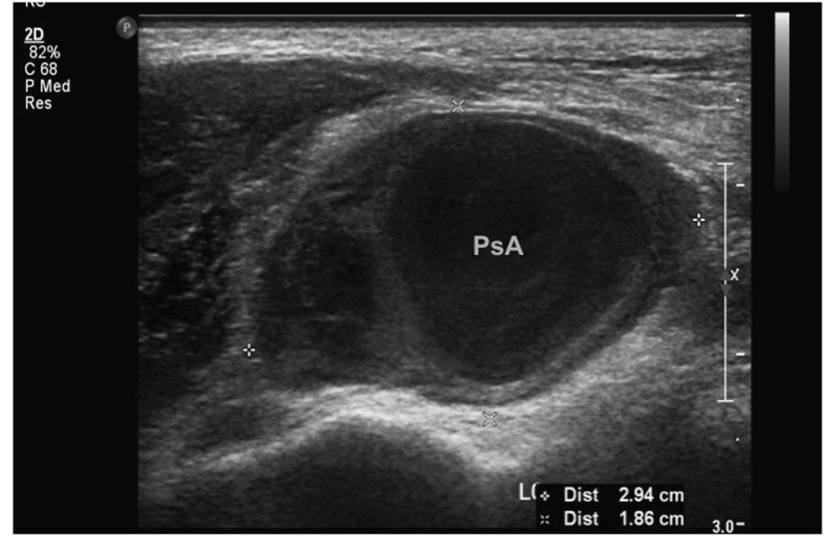

Figure 2. 2D ultrasound image showing maximal diameter of anterial tibial pseudoaneurysm.

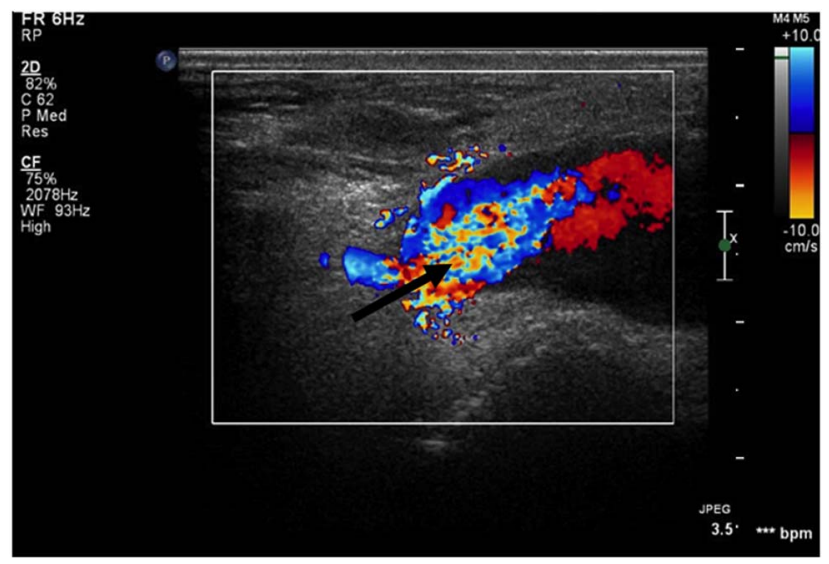

Figure 3. Colour Doppler ultrasound image of this patient's pseudoaneurysm. Blue $=$ blood flow toward probe, $\operatorname{Red}=$ blood flow away from probe, Arrow = area of high-velocity swirling.

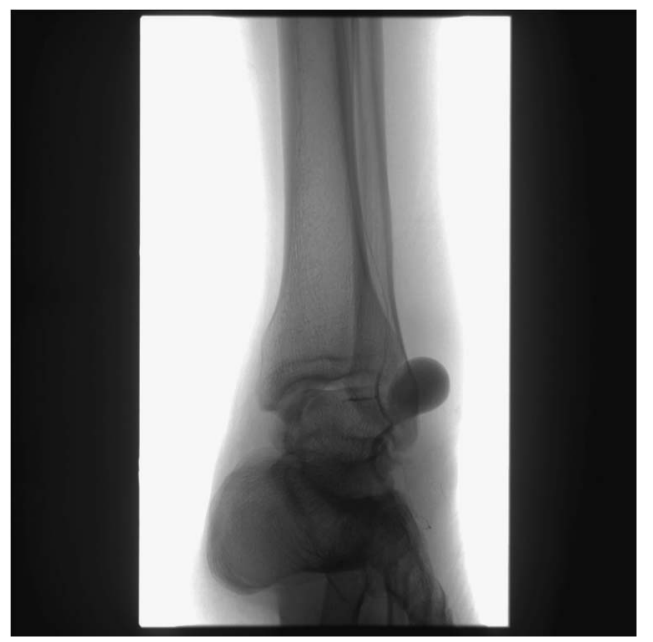

Figure 4. Angiogram image taken in the Interventional Radiology suite, showing saccular pseudoaneurysm located anterolateral to the talocrural joint.
A high index of suspicion is necessary to diagnose anterior tibial artery pseudoaneurysm in the absence of major trauma. A tender or pulsatile mass of the lower leg, signs or symptoms of neurovascular insufficiency, or disproportionate pain or swelling after any lower limb injury or invasive medical procedure should prompt consideration of this diagnosis. Presentation may be delayed by months, following the initial insult. ${ }^{3,5,17}$ As in our case, the differential diagnosis often includes infectious processes such as abscess formation. Varying degrees of swelling, fluctuance, erythema, pain, leukocytosis and other non-specific findings may lead the clinician to consider empiric incision and drainage of an arterial lesion presumed to be an abscess. Auscultation for a bruit during the initial assessment-which was present and easily audible upon subsequent examination of our patient-would have confirmed our initial suspicion of a vascular problem. We propose that bedside ultrasound, employed by a trained emergency physician, may be helpful in avoiding this potentially serious iatrogenic complication. Other advantages of this approach include decreased time to diagnosis and definitive therapy, and decreased ED length of stay. ${ }^{18}$

While angiography remains the gold standard for diagnosis and treatment planning, duplex ultrasound is the accepted modality for initial non-invasive imaging. ${ }^{11,16}$ Sensitivity and specificity of duplex ultrasonography in the diagnosis of pseudoaneurysm are estimated at $94 \%$ and $97 \%$, respectively. ${ }^{19}$ Bedside diagnosis of post-traumatic arterial pseudoaneurysms of the face and lower limb, using point-of-care ultrasonography performed by the ED physician, has indeed been described in a few case reports of single patients. ${ }^{18,20-22}$ The bedside technique most commonly described consists of linear ultrasound probe placement directly over the area of maximal swelling (or bruit/ thrill, if present). ${ }^{18,20}$ The anechoic pseudoaneurysm cavity may be pulsatile and is commonly surrounded by hypoechoic thrombus (Figure 2). ${ }^{18,22}$ This sonographic appearance may closely resemble that of an abscess cavity with debris. ${ }^{21}$ The use of color Doppler is particularly valuable in differentiating the two. Characteristic findings of pseudoaneurysm include bidirectional blood flow in the pseudoaneurysm neck, pulsatile flow in the cavity (Figure 3), and the "yin-yang sign" (swirling blood in the pseudoaneurysm resembling the ancient symbol). ${ }^{20}$ The accuracy of bedside ultrasound in the diagnosis of arterial pseudoaneurysms has not yet been elucidated. 
Current first-line therapies for arterial pseudoaneurysm include ultrasound-guided thrombin injection, and endovascular procedures including embolization and coiling, as described in our patient. ${ }^{4,16,23,24}$ First-attempt success rates with these procedures are high (>90\%) and complication rates are low. ${ }^{16,25}$ Ultrasound-guided compression therapy is also reported to be effective and safe, though more resource intensive. ${ }^{6,16,26}$ A minority of patients require open surgical resection, particularly those with infected or rapidly expanding pseudoaneurysms, skin necrosis, limb ischemia, or neurovascular compromise. ${ }^{16,27,28}$ The literature also documents successful conservative management, i.e., observation only, of painless arterial pseudoaneurysms measuring $<2 \mathrm{~cm}^{11}$ One year after coiling of his pseudoaneurysm, our patient is asymptomatic and has no functional limitations. He remains active and plays sports regularly.

\section{CONCLUSION}

Disproportionate pain and/or swelling after lower limb injury, even when the insult is apparently innocuous or the presentation is delayed, should raise the clinician's index of suspicion for these uncommon vascular lesions. Duplex ultrasound is well established as the initial gateway to definitive diagnosis. Bedside ultrasound is rapidly becoming a vital extension of the emergency physician's physical examination. The indications for, and applications of, ED targeted ultrasound are expanding. Imaging findings in this case suggest that the lesion may have been detectable by an ED physician using ultrasound at the bedside. As with other conditions, this has the potential to facilitate more timely diagnosis and definitive treatment for patients. More research is needed to establish the diagnostic accuracy and utility of point-of-care ultrasound in the evaluation of suspected lower limb vascular lesions.

Competing Interests: This research received no specific grant funding from any funding agency, commercial or not-for-profit sectors. No conflict of interest declared.

\section{REFERENCES}

1. Franz RW, Shah KJ, Halaharvi D, et al. A 5-year review of management of lower extremity arterial injuries at an urban level I trauma center. 7 Vasc Surg 2011;53(6):1604-10.

2. Haddock NT, Weichman KE, Reformat DD, et al. Lower extremity arterial injury patterns and reconstructive outcomes in patients with severe lower extremity trauma: a 26-year review. 7 Am Coll Surg 2010;210(1):66-72.

3. Lädermann A, Stern R, Bettschart V, et al. Delayed posttraumatic pseudoaneurysm of the anterior tibial artery mimicking a malignant tumor. Orthopedics 2008;31(5):500.

4. Jacobs E, Groot D, Das M, et al. Pseudoaneurysm of the anterior tibial artery after ankle arthroscopy. 7 Foot Ankle Surg 2011;50(3):361-3.

5. Verbrugghe P, Vandekerkhof J, Baeyens I. Pseudoaneurysm of the anterior tibial artery: a complication of ankle arthroscopy. Acta Chir Belg 2011;111(6):410-1.

6. Jang EC, Kwak BK, Song KS, et al. Pseudoaneurysm of the anterior tibial artery after ankle arthroscopy treated with ultrasound-guided compression therapy. A case report. 7 Bone foint Surg Am 2008;90(10):2235-9.

7. Mariani PP, Mancini L, Tara L, et al. Pseudoaneurysm as a complication of ankle arthroscopy. Artbroscopy 2001; 17(4):400-2.

8. Murashita T, Yasuda K, Takigami T, et al. Mycotic aneurysms of the bilateral tibioperoneal trunks associated with bacterial endocarditis: a case report. Int Angiol 1997;16(3):176-9.

9. McKee MA, Ballard JL. Mycotic aneurysms of the tibioperoneal arteries. Ann Vasc Surg 1999;13(2):188-90.

10. Tomescot A, Mackowiak E, Coggia $M$, et al. Pseudoaneurysm of the anterior tibial artery after a tibial bone true-cut needle biopsy treated by an arterial resection and anastomosis. Ann Vasc Surg 2011;25(3):386 e13-5.

11. Shah S, Fischman A, Marin M, et al. Spontaneous tibioperoneal trunk and anterior tibial artery pseudoaneurysms. Vasc Med 2012;17(3):164-7.

12. Shalhoub J, English B, Byard M, et al. Blunt trauma of the anterior tibial artery in professional footballers. Vasc Endovascular Surg 2011;45(2):195-7.

13. Marron CD, McKay D, Johnston R, et al. Pseudo-aneurysm of the anterior tibial artery, a rare cause of ankle swelling following sports injury. BMC Emerg Med 2005;14:5:9.

14. NKF-DOQI Clinical Practice Guidelines for Vascular Access. Management of complications: Optimal approaches for treating complications. Am $\mathcal{F}$ Kidney Dis 2001;37(Suppl 1):S163.

15. Jindal K, Chan CT, Deziel C, et al. Canadian Society of Nephrology Committee for Clinical Practice Guidelines. Hemodialysis clinical practice guidelines for the Canadian Society of Nephrology. 7 Am Soc Nephrol 2006;17(3 Suppl 1):S1.

16. Webber GW, Jang J, Gustavson S, et al. Contemporary management of postcatheterization pseudoaneurysms. Circulation 2007;115(20):2666-74.

17. Ramavath AL, Cornish JA, Ganapathi M, et al. Missed diagnosis of ankle pseudoaneurysm following ankle arthroscopy: a case report. Cases 7 2009;2:1-4.

18. Goksu E, Kucukyilmaz O, Soyuncu S, et al. Pseudoaneurysm of the anterior tibial artery detected by emergency medicine physician performing bedside ultrasound. Am 7 Emerg Med 2009;27(1):129.e3-e4.

19. Coughlin BF, Paushter DM. Peripheral pseudoaneurysms: evaluation with duplex US. Radiology 1988;168(2):339-42.

20. Goksu E, Yuruktumen A, Kaya H. Traumatic pseudoaneurysm and arteriovenous fistula detected by bedside ultrasound. 7 Emerg Med 2014;46(5):667-9. Epub 2014 Jan 25. 
21. Abdi A, Armijo E, Seif D, et al. Man with a forehead mass: detection of a forehead pseudoaneurysm with bedside ultrasonography. Case Rep Emerg Med 2014;2014:647175.

22. Jenq KY, Panebianco NL, Lee PA, et al. Diagnosis of a facial artery pseudoaneurysm using emergency bedside ultrasound. 7 Emerg Med 2010;8(5):642-4.

23. Mavili E, Donmez H, Ozcan N, et al. Endovascular treatment of lower limb penetrating arterial traumas. Cardiovasc Intervent Radiol 2007;30(6):1124-9.

24. Pan M, Medina A, Suarez de Lezo J, et al. Obliteration of femoral pseudoaneurysm complicating coronary intervention by direct puncture and permanent or removable coil insertion. Am $\mathcal{F}$ Cardiol 1997;80(6):786-8.
25. van Hensbroek PB, Ponsen KJ, Reekers JA, et al. Endovascular treatment of anterior tibial artery pseudoaneurysm following locking compression plating of the tibia. 7 Orthop Traum 2007;21(4):279-82.

26. Fellmeth BD, Roberts AC, Bookstein JJ, et al. Postangiographic femoral artery injuries: non-surgical repair with USguided compression. Radiology 1991;178(3):671-5.

27. Lumsden AB, Miller JM, Kosinski AS, et al. A prospective evaluation of surgically treated groin complications following percutaneous cardiac procedures. Am Surgeon 1994;60(2):132-7.

28. Saad NE, Saad WE, Davies MG, et al. Pseudoaneurysms and the role of minimally invasive techniques in their management. Radiographics 2005;25:S173-89. 